\title{
TEACHER AND PEER FEEDBACK IN AN EFL WRITING COURSE: WHAT DO STUDENTS NEED?
}

\author{
Thanakorn Weerathai, \& Ratsawadee Belardo \\ Rajamangala University of Technology Isan, Khon Kaen Campus (Thailand)
}

\begin{abstract}
Although teacher and peer feedback is essential in aiding students to progress in their writing skills and is encouraged in any writing class, some classroom circumstances may act to limit the feedback teachers and peers give or may make giving feedback impossible. Conditions that may limit feedback can include heavy teaching loads of teachers, large class sizes, insufficient language knowledge of peers, and cultural limits such as fear of causing loss-of-face or having a "kreng jai" attitude (fear of offending others). Taken together, these factors hinder straightforward feedback from both teachers and peers, impacting growth in student writing skills. This study aimed at finding out students' needs towards teacher and peer feedback in an English Writing for Daily Life course. Research instruments utilized were a four-point Likert scale questionnaire and semi-structured interview. Participants were 119 mixed-ability third and fourth-year undergraduate students majoring in Business Administration (Management), Accounting, and Mechanical Engineering at a university in the northeastern region of Thailand. Findings revealed that the majority of students had problems with content $(59.66 \%)$, vocabulary $(53.78 \%)$, and organization $(50.42 \%)$. Although these three aspects were their major problems in English writing, teachers emphasized giving feedback on mechanics (54.62\%), language use (50.42\%), and organization (48.74\%), while peers gave feedback more on surface-level features, i.e., vocabulary $(44.54 \%)$ and language use $(41.18 \%)$, despite their limitation of language knowledge. Based on the findings, this paper concluded that there was a mismatch between students' needs and feedback given by teachers and peers, where students needed sufficient feedback to improve their deep-level features, i.e., content and organization. Although students needed to receive more feedback to improve their content and organization, they also needed feedback on vocabulary, language use, and mechanics to improve the quality of their writing. Therefore, it is suggested that teachers give feedback focused on syntax to help students in terms of their language limitation, whereas peers should be trained to give feedback on content and organization to develop their critiquing skills.
\end{abstract}

Keywords: Teacher feedback, peer feedback, EFL writing.

\section{Introduction}

\subsection{Background}

Feedback has long been used and given to students as it helps to improve their writing skills. It helps students to not only write better but also to develop their confidence, encouraging them to learn collaboratively (Rollinson, 2005; Weerathai, 2019; Yu \& Hu, 2016). However, under some circumstances, teachers may limit to give feedback only on particular writing aspects such as language use and mechanics to save time due to their heavy teaching loads and large class sizes (Changpueng, 2009; Chinnawongs, 2001; Honsa, Jr., 2013) and leave out writing aspects that students may need, i.e., content and organization. On the other hand, students may give feedback on surface-level features to their peers such as vocabulary and language use, despite their language knowledge limitation, because this does not require skills to critique peers' work so that they do not have to offend others (Weerathai \& Arya, 2020). Regarding teaching and learning writing in the Thai context, these conditions make it challenging to alleviate the situation. Thus, this study would help teachers and educators to better understand students' needs in terms of feedback that they need in their writing as well as suggest what to do to minimize such challenges when giving teacher and peer feedback. 


\subsection{Purpose of study}

Although feedback is necessary to be given to students learning of writing, the given feedback, sometimes, does not cater to their needs due to the aforementioned classroom conditions. Hence, the purpose of this study was to find out the students' needs towards teacher and peer feedback in an English writing course so that it might help both teachers and peers to better give feedback that caters more to students' needs and to alleviate challenges in classroom.

\section{Methods}

\subsection{Research design and participants}

The design of this study was mixed-methods. A four-point Likert scale questionnaire and semi-structured interview were utilized as research instruments to find out students' attitudes towards teacher and peer feedback in an English Writing for Daily Life course in the first semester of the academic year 2019. Participants were 119 mixed-ability third and fourth-year undergraduate students majoring in Business Administration (Management), Accounting, and Mechanical Engineering at a university in the northeastern region of Thailand, aged 20-24 including male and female. The English writing proficiency of most students was at the intermediate and low levels.

\subsection{Data collection}

The questionnaire was distributed to 119 students towards the end of the course of study. It took about 10-15 minutes for the students to complete the questionnaires. All questionnaires were returned $(100 \%)$. Moreover, the semi-structured interview was conducted with 18 students including 6 high, 6 intermediate, and 6 low-proficiency students. The interviewees were asked to report and elaborate their views in Thai regarding teacher and peer feedback. Each interview took about 10-15 minutes. All interviews were audio recorded.

\subsection{Data analysis}

The criteria of the questionnaire were set prior to the analysis to interpret the data. The data were interpreted as follows:

1. Problem areas in writing

$$
1=\text { not problematic at all }(1.0-1.49) \quad 2=\text { not very problematic }(1.5-2.49)
$$

$3=$ problematic $(2.5-3.49)$

2. Frequency of feedback given by teachers and peers

$$
\begin{array}{ll}
1=\text { not very often at all }(1.0-1.49) & 2=\text { not often }(1.5-2.49) \\
3=\operatorname{often}(2.5-3.49) & 4=\text { very often }(3.5-4.0)
\end{array}
$$

Data obtained from the questionnaires were calculated by using descriptive statistics. The statistical methods used to analyze the data were percentage, arithmetic mean, and standard deviation. The percentages reported in this paper showed only of Scale 3, i.e., problematic and often.

In addition, data gained from the semi-structured interviews were analyzed using content analysis. It was used to probe into two main areas: a need for teacher feedback and a need for peer feedback. After that, data were transcribed, tallied, and reported.

\section{Results}

Results from the questionnaire showed that many students had problems with writing clear topic sentences and relevant supporting details (59.66\%), using appropriate and meaningful words and idioms $(53.78 \%)$, and organizing and sequencing sentences within the paragraph $(50.42 \%)$. Table 1 shows problem areas in writing of the students.

Table 1. Problem areas in writing of the students.

\begin{tabular}{|l|l|l|l|}
\hline \multicolumn{1}{|c|}{ Aspects of writing } & Mean & \multicolumn{1}{|c|}{ SD } & Percentage \\
\hline 1. Content (e.g., thesis statement, topic sentence, and supporting ideas) & 2.66 & 0.68 & 59.66 \\
\hline 2. Organization (e.g., sentence/paragraph organization and sequencing) & 2.58 & 0.71 & 50.42 \\
\hline 3. Vocabulary (e.g., words and idioms) & 2.65 & 0.78 & 53.78 \\
\hline 4. Language use (e.g., grammar and structure) & 2.87 & 0.87 & 49.58 \\
\hline 5. Mechanics (e.g., spelling and punctuation) & 2.55 & 0.71 & 49.58 \\
\hline
\end{tabular}


Despite of the fact that many students had problems with content, vocabulary, and organization, teachers gave feedback more on spelling and punctuation (54.62\%), grammar and structure (50.42\%), and organizing and sequencing sentences (48.74\%).

As for peers, despite having problems with content, vocabulary, organization, and language knowledge, they emphasized giving feedback on surface-level features, i.e., vocabulary (44.54\%) and language use (41.18\%). Tables 2 and 3 illustrate frequency of feedback given by teachers and peers on each writing aspect.

Table 2. Frequency of feedback given by teachers.

\begin{tabular}{|l|l|l|l|}
\hline \multicolumn{1}{|c|}{ Aspects of writing } & \multicolumn{3}{c|}{ Feedback given by teachers } \\
\cline { 2 - 4 } & \multicolumn{1}{c|}{ Mean } & SD & Percentage \\
\hline 1. Content (e.g., thesis statement, topic sentence, and supporting ideas) & 2.78 & 0.77 & 46.22 \\
\hline 2. Organization (e.g., sentence/paragraph organization and sequencing) & 2.79 & 0.75 & 48.74 \\
\hline 3. Vocabulary (e.g., words and idioms) & 2.88 & 0.77 & 47.06 \\
\hline 4. Language use (e.g., grammar and structure) & 2.86 & 0.76 & 50.42 \\
\hline 5. Mechanics (e.g., spelling and punctuation) & 2.72 & 0.71 & 54.62 \\
\hline
\end{tabular}

Table 3. Frequency of feedback given by peers.

\begin{tabular}{|l|l|l|l|}
\hline \multicolumn{1}{|c|}{ Aspects of writing } & \multicolumn{3}{c|}{ Feedback given by peers } \\
\cline { 2 - 4 } & \multicolumn{1}{c|}{ Mean } & \multicolumn{1}{c|}{ SD } & Percentage \\
\hline 1. Content (e.g., thesis statement, topic sentence, and supporting ideas) & 2.35 & 0.78 & 36.97 \\
\hline 2. Organization (e.g., sentence/paragraph organization and sequencing) & 2.31 & 0.75 & 36.13 \\
\hline 3. Vocabulary (e.g., words and idioms) & 2.45 & 0.77 & 44.54 \\
\hline 4. Language use (e.g., grammar and structure) & 2.38 & 0.78 & 41.18 \\
\hline 5. Mechanics (e.g., spelling and punctuation) & 2.26 & 0.79 & 35.29 \\
\hline
\end{tabular}

Regarding the results of the interviews, most of the students addressed that feedback was essential and should be given to students to aid them to progress in their writing, especially feedback given by teachers. This would help them see their strengths and weaknesses in their writing, which could improve their writing skills and make them feel confident to write.

In terms of a need for teacher feedback, many of the high-proficiency students revealed that they preferred teacher feedback to peer feedback. They viewed teacher feedback as reliable and useful, and that they could trust the feedback. They suggested that teachers give sufficient feedback on the areas that they had most difficulties with such as content and vocabulary. Although the high-proficiency students viewed the need for teacher feedback more on these areas than the other areas, they revealed that they also expected teachers to give feedback on grammar and structure because they did not know whether their peers could give correct feedback to them.

As for the intermediate and low-proficiency students, they revealed that they were satisfied with teacher feedback. Particularly the intermediate students, they felt that teacher feedback was useful and straightforward. Feedback given by teachers could benefit them more than peer feedback, especially that given on the areas of content and vocabulary. For the low-proficiency students, although having mentioned that they liked teacher feedback as well, they reported that feedback on content and organization was insufficient. More feedback in terms of examples on the areas of writing topic sentences and supporting sentences should have been given to the students. This would help them have more examples and sentence models to follow. The following are examples of the students' views on teacher feedback that represent the majority of each proficiency level.

I think teacher feedback was useful and it should be given to students. I could see my strengths and weaknesses in my writing. However, the teacher should give more feedback on vocabulary and content. I think vocabulary was very important. If I knew more vocabulary, I would be able to write and understand the texts better. So, I think the teacher should give more feedback on vocabulary to expand our vocabulary knowledge. (Yaya-High)

I think teacher feedback was beneficial. When my partner could not see my writing problems, the teacher could clarify those problems, which helped me improve my work. However, I think the teacher did 
not give enough feedback on content and vocabulary. It was quite difficult for me to write a clear topic sentence and choose the right words in my supporting sentences. (Barry - Intermediate)

Teacher feedback was useful, but I would like the teacher to provide more examples in terms of writing clear topic sentences, supporting sentences, and organizing paragraph. Sometimes I did not know what to write and revise my work because I did not have enough examples to follow. (Bella-Poor)

In terms of a need for peer feedback, many of the high-proficiency students did not find it very useful. Since the majority of the students gave feedback on surface-level features, despite their language knowledge limitation, the high-proficiency students found it hard to trust such feedback. They suggested that teachers also give feedback on the aspect of syntax other than those on global aspect.

As for the intermediate and low-proficiency students, they reported that peer feedback was useful, especially those of low-proficiency level. They could learn writing collaboratively making them feel more confident to express their ideas and talk more openly with their friends. Although feedback was not very constructive when given on the aspect of syntax, they were still satisfied with having peer feedback employed in the classroom because it helped them learn with each other and did not find the classroom atmosphere too boring. The following are examples of the students' views on peer feedback that represent the majority of each proficiency level.

I think peer feedback was not very useful. Although it allowed us to exchange ideas, the feedback was not clear. When I asked my friend about my minor supporting sentences whether they were relevant to the major supporting sentence, she said that she was not sure. Sometimes she gave me feedback on grammar and I asked her why it was wrong, she could not explain why. She said that she just felt it wrong. I think she did not really know the answers. (Lisa-High)

Peer feedback was good. It allowed us to discuss and share ideas more openly. However, the feedback was not constructive. My partner said that my grammar seemed wrong, but she could not tell me why. So, it was hard for me to revise my work. (Mario - Intermediate)

I think it was good. Sometimes the students were not brave enough to ask the teachers directly and peer feedback allowed us to communicate and exchange ideas easier and more openly. The classroom atmosphere was not so boring. (JJ-Low)

In brief, teacher and peer feedback were useful methods to employ in this writing class. Although there was a mismatch between the students' needs and the feedback given by teachers and peer due to some classroom conditions, it was evident that the students were satisfied with teacher and peer feedback in general because it helped them to not only gradually improve their writing skills but also to boost their confidence to learn writing collaboratively.

\section{Discussion}

This study explores the students' needs towards teacher and peer feedback in an EFL English writing course. Results from the questionnaire and interview indicate a mismatch between feedback given to the students and their needs. The following suggest possible areas when employing teacher and peer feedback in any EFL writing class.

\subsection{Providing an explicit peer feedback training}

Regarding the results from the questionnaire where peers emphasized giving feedback on surface-level features, despite their limitation of language knowledge, suggest that an explicit peer feedback training is required to train students to give more feedback on deep-level features. Research (Min, 2016) on effect of teacher modeling and feedback on EFL students' peer feedback skills revealed that peer feedback training was very important and should be given sufficiently and repeatedly to students to train them on cognitive aspects. This could not only encourage them to think and critique their partners' work straightforwardly but also most cater to their needs for feedback.

\subsection{Giving teacher feedback on the aspect of syntax}

Evidence from the interview where students, especially those of high and intermediate proficiency levels, revealed that feedback from peers on the aspect of syntax was not very constructive and useful. Studies (Dressler, Chu, Crossman \& Hilman, 2019; Ekş1, 2012) on peer feedback in writing showed that students, without being exposed to explicit training, gave more feedback on surface-level features. However, the feedback was not constructive enough to help their peers to revise their work. It is suggested that teachers give feedback on the aspect of syntax to help students in terms of their language problems, and peers should be trained to give more feedback on the aspects of content and organization. 


\subsection{Providing sufficient reading input to students}

Evidence from the interview where students reported that they needed the teachers to give more feedback on the areas of content and vocabulary suggests that students had insufficient vocabulary knowledge and wider outlook on world knowledge; hence, they depended more upon teacher support. Research (Weerathai \& Arya, 2020) on the effectiveness of self-monitoring and peer feedback strategies implemented in an English essay writing class revealed a slight improvement on students' post-test writing due to providing insufficient reading input to the students. This suggests that providing sufficient reading input to students is necessary as it helps to expand their vocabulary knowledge and to expose them to a wider outlook on world knowledge so that they do not have to often depend upon teacher feedback and are able to learn from their peers.

\section{Conclusion}

This study shows that students appreciated the importance and benefits of both teacher and peer feedback. Although there was a mismatch of the needs for the given feedback between teachers and students, where both teachers and peers could have provided feedback more on deep-level features than those on surface-level features, it is recommended to give teacher and peer feedback in any writing course to facilitate students in learning writing, sharpening their critiquing skills, and exposing them to a broader outlook on world knowledge.

\section{Limitations} as follows:

This study was conducted over a period of one semester; hence, there were two major limitations

1. The students were not given sufficient and explicit peer feedback training. It might be the case that they gave feedback on writing aspects that they did not have to directly criticize and offend their peers, i.e., surface-level features.

2. The tasks that the students worked on were mostly about paragraph elements encompassing paragraph topic, topic sentence, supporting sentences, concluding sentence, transitions, and paragraph organization. It might be the case that the students correlated feedback components to the specific tasks rather than to writing in general.

\section{References}

Changpueng, P. (2009). The Development of an English Writing Course Based on the Genre-Based Approach for Undergraduate Engineering Students at King Mongkut's University of Technology North Bangkok (Unpublished doctoral dissertation). Chulalongkorn University, Bangkok.

Chinnawongs, S. (2001). In search of an optimal writing feedback strategy. PASAA, 31, $27-43$.

Dressler, R., Chu, M., Crossman, K., \& Hilman, B. (2019). Quantity and quality of uptakes: Examining surface and meaning-level feedback provided by peers and an instructor in a graduate research course. Asessing Writing, 39, 14-24. doi.org/10.1016/j.asw.2018.11.001

Ekş1, G.Y. (2012). Peer review versus teacher feedback in process writing: How effective? International Journal of Applied Educational Studies (IJAES), 13(1), 33-48.

Honsa, S., Jr. (2013). Self-assessment in EFL writing: A study of intermediate EFL students at a Thai university. Voices in Asia Journal, 1(1), 34-57.

Min, H.T. (2016). Effect of teacher modeling and feedback on EFL students' peer review skills in peer review training. Journal of Second Language Writing, 3(1), 43-57.

Rollinson, P. (2005). Using peer feedback in the ESL writing class. ELT Journal, 59(1), 23-31.

Weerathai, T. (2019, June). Self-monitoring and peer feedback strategies: Challenges and opportunities in the EFL writing class. Paper presented at the International Conference on Education and New Developments 2019, Porto, Portugal. Retrieved from http://end-educationconference.org/wpcontent/uploads/2019/06/Education-and-New-Developments_2019_Vol_II.pdf

Weerathai, T., \& Arya, T. (2020). The effectiveness of implementing self-monitoring and peer feedback strategies with mixed-ability students in an English essay writing class. Journal of Rangsit University: Teaching \& Learning, 14 (1), 33-48.

$\mathrm{Yu}, \mathrm{S} .$, \& Hu, G. (2016). Can higher-proficiency L2 learners benefit from working with lower-proficiency partners in peer feedback? Teaching in Higher Education, 22(2), 178-192. doi:10.1080/13562517.2016.1221806 